\title{
JUSTICE IN ROBES (A JUSTIÇA DE TOGA)
}

\author{
CARLOS ALBERTO MOLINARO*
}

DWORKIN, Ronald. Justice In Robes. Cambridge, Massachusetts: Harvard University Press, April, 2006. 320 pp. ISBN: 0674021673. Formato: Hardcover.

Ronald Dworkin, no seu livro “Justice in Robes”, de certa forma, uma resposta ao livro de Cass Sunstein, Radicals in Robes (Basic Books, 2005) ${ }^{1}$, apresenta-se com uma provocante coleção de ensaios que intentam responder a seguinte pergunta: "Figuram as considerações morais entre as condições de verdade das proposições do direito e, nesse caso, como?” (p. 5). Os advogados, os juízes, os filósofos do direito e os cientistas políticos concordam que as proposições do direito (da norma jurídica), isto é, os enunciados normativos têm um verdadeiro-valor. Por exemplo, é verdadeira ou falsa a afirmativa que "a norma constitucional americana permite que o presidente ordene que os estrangeiros suspeitos de atos de terrorismo sejam torturados" (p. 2 - Obs.: o que representa esta verdade-valor é, naturalmente, outra matéria). À pergunta polêmica que faz Dworkin e, finalmente, as respostas são: se a verdade-valor de tais enunciados normativos dependem de considerações morais substantivas? Segundo Dworkin, os princípios morais pertencem necessariamente ao jogo das verdades-condições para os enunciados normativos, e "Justice in Robes" consiste em argumentos críticos e construtivos para esta reivindicação. Assim, de um lado, vai criticar as posições que se divorciam dos princípios mais que sobre as perguntas relativas à validez dos enunciados normativos e, de outro lado, ele intenta mostrar que tal divórcio é de fato impossível. O ponto central de "Justice in Robes", ademais dos ensaios críticos que incluem "Pragmatismo e Direito", "Pluralismo Moral”, e "Pós-escrito de Hart e o Objetivo da Filosofia Política”, está no ataque que faz ao que, metaforicamente, denomina de aproximação archimediana, de alguns à teoria e a filosofia legal. Utilizado metaforicamente o princípio de Archimedes,

\footnotetext{
* Doutor em Direito, Professor da PUCRS

${ }^{1}$ O livro de Dworkin tampouco reconhece em Radicals in Robes, em qualquer de suas notas de pé de página, ou no índice ou no próprio título, Justice in Robes, mas parece uma paródia do título de Sunstein, especialmente pelo alargado do texto de Dworkin em que critica Sunstein, atribuindo-lhe um pragmatismo cego, amoral e que tem medo de defender um forte standard que simbolize valores morais como a Justiça e a Igualdade na Ciência do Direito (cf. Justice in Robes, pp. 63-77; mas atente-se que quase todas as críticas de Dworkin a Sunstein são de um texto deste, mais antigo (1996): Legal Reasoning and Polítical Conflict, onde estão bem identificadas as idéias desenvolvidas em Radicals in Robes.
} 
por alguns, ditos archemedianos, Dworkin discute e insiste na divisão afiada entre dois níveis do discurso jurídico (um “emergido” outro em “impulsão”): “o discurso dos não-filósofos que refletem e que discutem sobre o que é direito ou censurável, vale dizer, o que é correto e o que é incorreto, legal ou ilegal, verdadeiro ou falso, formoso ou mundano" e o metadiscurso, em que tais demandas "são classificadas e atribuídas às categorias filosóficas” (p. 141). No direito, de acordo com este acercamento, enquanto advogados e juízes se comprometem com o discurso de primeiro nível que incorpora o que é legal e o que é ilegal, os filósofos do direito e os cientistas políticos se comprometem com o discurso de segundo nível, ou com o metadiscurso acerca do status e das condições-de-verdade dessas demandas. Para Dworkin, quando nos aproximamos da perspectiva archimediana, nos “desencaminhamos" (no sentido de uma má-orientação epistemológica), pois é inaceitável separar os enunciados normativos ou proposições legais (que os archimedianos defendem, ao incluir-se no discurso de primeiro nível) dos enunciados (proposições) descritivos acerca do status das demandas de primeiro nível. Contra esta perspectiva, intenta apontar que não há nenhum vazio entre as demandas normativas que ele denomina de "disciplina interpretativa" (como o direito) e as demandas descritivas de uma metadisciplina correspondente (como a filosofia do direito). Ao contrário, demonstra que as perguntas acerca das verdades-condições das proposições (ou enunciados) normativas (perguntas endereçadas à Justiça de Toga) se são perguntas normativas, logo, as respostas às demandas são em termos normativos. A perspectiva archimediana se equivoca em três aspectos bem diferentes, em doutrinas “desencaminhadas": o pragmatismo legal (como em Rorty e Posner), o positivismo legal (como em Hart y Coleman), e o pluralismo moral (como em Berlín), isto é, Dworkin intenta explicar com detalhe, primeiro, a anatomia de cada posição e a fonte de seu compromisso com a divisão normativa/descritiva e, segundo, as razões do por que a posição archimediana é equivocada, daí vai dizer textualmente: “unsound”, enferma, débil, insana, falha.

Sobre o pragmatismo - sustenta Dworkin - em geral é um caso paradigmático da perspectiva archimediana do direito e da filosofia em geral, neste viés, para um pragmatista, a pergunta sobre "o que é realmente o direito", é uma pergunta vã ou “sem sentido” (p. 37). Melhor, nós necessitamos reconhecer que não há uma realidade legal externa a que a nossa demanda se refere. Ao contrário, os juízes "devem decidir os casos a eles apresentados” prolépticamente, “ao estilo consequencialista” (p. 21). Em outras palavras, segundo os pragmatistas, sugerir que os princípios morais servem de condições de verdade para as proposições do direito (ou os enunciados normativos jurídicos), como sustenta Dworkin, é entender mal a natureza do discurso legal: as proposições do direito (ou qualquer jogo de proposições em matéria jurídica) não se referem, em absoluto, a alguma realidade externa; portanto, o nosso melhor vetor para encontrar respostas legais aceitas como válidas, é uma prolépse (antecipação do que vai adiante) fundada na valoração das respostas legais mais úteis. Sustenta Dworkin que a perspectiva pragmática do Direito, é “filosoficamente confusa” (p. 23). De acordo com o pragmatismo, há uma diferença fundamental entre duas espécies de demandas, por exemplo, (a) ‘a bestialidade é ilegal’ e, (b) ‘é uma verdade objetiva que a bestialidade é ilegal’. Para os pragmatistas (a) é uma verdade, uma demanda normativa incorporada 
no locus eloqüente de um discurso de primeira ordem (não-filosófico); de outra parte, (b) é uma demanda metalegal descritiva concernente ao status de (a). Esta demanda metalegal, um pragmatista, assim o sustenta, é falsa desde que exige que (a) seja verdade em virtude de sua relação a uma realidade independente. Dworkin expõe que não há nenhuma diferença de fato entre (a) e (b) e que o pragmatista está meramente “intentando seqüestrar-nos a algum nível filosófico místico” (p. 43), o nível que se supõe transcende ao discurso legal, e se presume que isso só está acessível aos filósofos (como aos teóricos do Direito), mas não aos advogados e juízes. Ao contrário dos pragmatistas, Dworkin sustenta que todo o discurso acerca do direito pertence ao mesmo nível, um nível normativo que atravessa como uma linha horizontal muito precisa as expressões em (a) e (b), sendo esses nada mais do que, nas palavras de Dworkin, "uma inflação verbal” (p. 42).

A obra de H. L. A. Hart, The Concept of Law (que Dworkin em "Justice in Robes" usa como um case-study do positivismo legal) é outra versão do archimedianismo em filosofia do direito. Segundo Hart, e contrariamente a perspectiva de Dworkin, perguntas como "o que é o direito”, “o que é a lei”, ou “o que é uma lei o válida, ou direito válido" são questões descritivas no sentido de que devem ser contestadas em termos de análises (em lugar de uma interpretação normativa) da prática legal. Ademais, Hart defende que essas questões são filosóficas e devem ser respondidas pelos teóricos que a tratam com metateoria, e não por operadores do direito (advogados e juízes) que estão comprometidos com a própria prática legal. Dworkin discrepa. A teoria de Hart, diz Dworkin, não demonstra que não há uma descrição (não-normativa) à resposta da pergunta que envolva a lei (norma) em geral e ao que seja uma lei (norma) válida em particular, tudo aplicável ao direito. Uma resposta descritiva seria possível, como é possível a descrição conceitual de espécies como "bachelor" [incluído aí o nosso "bacharel", que ademais pode ser "solteiro"], ou conceitos como "gold" ou "tiger". Veja-se que aí, e neste caso, necessitamos de um acordo semântico intensional [como categoria lingüística: intensional/extensional] do conceito (como em "bachelor") ou pelo menos com respeito a seus "casos” (como em "tiger”) para uma análise possível. Mas, para 'lei’ ou ‘direito’ (e ‘lei válida’ e ‘direito válido’) a formulação conceitual é sempre interpretativa. E, se este é o caso, então se deve apelar à prática legal para clarificar o conceito que o direito requer, ou pelo viés empírico de colecionar os dados relativos às práticas legais reais, através do acervo da cultura desenvolvida em momentos temporais bem marcados, onde se pode colher concepções de direito e direito válido de modo incontestado. Dworkin demonstra que o projeto de Hart, não satisfaz qualquer destas condições: de um lado, em $O$ Conceito de Direito (como outros tratados positivistas) não se apoia em conclusões com adequada evidência empírica (este, sem dúvida, não é seu equívoco principal, já que Hart afirma seu projeto como filosófico em lugar de sociológico); de outro lado, é simplesmente falso que 'direito' e 'direito válido' são conceitos incontestados: argumentos continuados concernentes ao que é direito e o que é direito válido requerem que se mostre claramente que “não há qualquer convenção” implicativa à lei constitucional em geral, vale dizer, não se pactua constitucionalmente sobre o direito e sua validade que, na lei fundamental, já estão postos. Assim, Dworkin conclui que o positivismo também não mostra 
(ademais de compartir com os equívocos do pragmatismo) que uma resposta completamente descritiva às questões legais fundamentais é possível.

Além do pragmatismo e do positivismo, o pluralismo moral desafia o entendimento de Dworkin. Segundo o pluralismo moral [como pensado por Berlín] este "é uma verdade conceitual” sobre nossos valores e, pois, entram inevitavelmente em conflito, deste modo, “as colisões de valores”, por conseqüência, são como são valores colidentes frente ao que somos, vale dizer, o ser dos valores e o ser que somos. Esta perspectiva desafia a posição de Dworkin, pois na sua perspectiva as perguntas que envolvem o que é direito válido e o que se requer para tal, podem aproximar-se e, também, podem ser contestadas atraindo princípios morais gerais. Aqui é o caso de conceitos muito trabalhados por Berlín, como liberdade e igualdade (e que muito amiúde entram em conflito). Neste sentido, o pluralismo moral é para Dworkin outra perspectiva archimediana, quando intenta acercar-se à filosofia. Dworkin vai afirmar que é possível a dissolução dos conflitos, entre liberdade e igualdade, desde que respeitados os direitos morais dos outros.

Em síntese, Justiça de Toga desafia-nos, com razões morais justificatórias (internas ao direito). Desafia-nos com a pergunta: "o que faz que um enunciado normativo, ou mesmo, o direito abstratamente considerado, seja falso ou verdadeiro?”. Uma resposta a esta pergunta nos leva ao estudo e a crítica, como fez Dworkin, a seu modo, de doutrinas instigantes como: pragmatismo, positivismo e pluralismo. Este desafio faz de Justice in Robes um percurso para a metafísica, a lingüística, a ética e a política e o direito. Uma pergunta final: qual a importância das convicções morais de um julgador, quando ele indaga sobre o que é o direito? Todos nós de um modo geral temos respostas para esta indagação, elas vão do "nada” ao “tudo”. Portanto, qualquer intento de resposta deve levar em consideração um complexo percurso (semântico, jurisprudencial e doutrinário) onde o pavimento está entretecido por um complexo normativo moral. Por isso é tão importante para Dworkin a soberania do princípio moral na interpretação legal e constitucional.

Neste livro vemos que Dworkin intenta demonstrar que o pragmatismo está vazio como teoria do direito, que o pluralismo de valor entende ou entendeu mal a natureza dos conceitos morais, que o originalismo constitucional reflete uma perspectiva empobrecida do papel de uma Constituição na sociedade democrática, e o positivismo contemporâneo está fundado numa semântica equivocada, e tem um modelo errôneo da natureza da autoridade. Dworkin, neste livro aponta uma crítica bastante severa e não sem fundamento, para os trabalhos de Isaiah Berlín, Richard Posner, Cass Sunstein, Antonin Scalia, e Joseph Raz, desde um texto lúcido e lógico, ainda que não o aceitemos em sua integralidade, sobre os papeis de justiça e do direito. 